\title{
A SiC based 2-Level Power Converter for Shape- and-Space-Restricted Aerospace Applications
}

\author{
U. Nasir, S. Chowdhury, A. La Rocca, Y. Chen, T. Yang, P. Wheeler, C. Gerada and S. Bozhko \\ Power Electronics and Machine Control (PEMC) Group \\ The University of Nottingham, UK \\ Usman.Nasir@nottingham.ac.uk
}

\begin{abstract}
Recent advancements in the power electronic device technologies, such as wide-band-gap devices including SiliconCarbide ( $\mathrm{SiC}$ ) and Galium-Nitride (GaN), are acting as an enabling factor in development of compact power electronic systems. More specifically, the concept of More Electric Aircraft (MEA), which requires the aircraft's pneumatic systems to be replaced by electrical systems, can therefore greatly benefit from these emerging technologies in reduction of weight and volume of the aircraft such that range of aircraft can be increased. Various functions of aircraft e.g. actuation and engine-starting in MEAs are performed by power electronic converter based systems. With $\mathrm{SiC}$ and GaN devices, converters with densities even up to $70 \mathrm{~kW} / \mathrm{L}$ are easily achievable only when the envelope of the converter is cubical and not restricted. However, in case when a specific envelope is provided by the aircraft manufacturer, the component selection, layout and the design of power electronic converter to achieve high power density, within the restricted envelope, becomes extremely challenging. This paper presents the design of a circular-shaped $17.5 \mathrm{~kW} / \mathrm{L}-97.6 \%$ efficient- SiC based two-level (2L) inverter for aircraft applications. Furthermore, the feasibility and design of the converter are supported by the experimental results rated at a power of $13 \mathrm{~kW}$.
\end{abstract}

Keywords-two-level SiC converter; power converter in aircraft; space-restricted $\mathrm{SiC}$ design; $\mathrm{SiC}$ gate drive

\section{INTRODUCTION}

The idea of employing electrical power systems in the aircrafts is helping the air transportation systems in making them environmentally responsible and greener. This is because replacing the pneumatic systems with electrical reduce the emissions and fuel consumptions [1,2] leading to an increase in the range of aircraft. The mentioned concept is usually referred in literature as 'More Electrical Aircraft (MEA)'. In MEA, the increased electrical loads which perform the key functions such as actuation, anti-icing, de-icing, starting of engine and air-conditioning must perform these operations with minimum losses [3]. This puts a constraint on not only the loads but also the source and the electrical network systems to be efficient and high in power density. For instance, considering the MEAs, Permanent-Magnet (PM) machines have come up as an emerging technology in aerospace applications due to their features such as simplicity, high power density and high speed operation [3-5]. The PM machine in a MEA is usually driven by a Voltage Source Converter (VSC) such that the VSC operates in inverter mode when functions such as actuation or engine starting is required. For instance, such an application of VSC in MEAs is illustrated

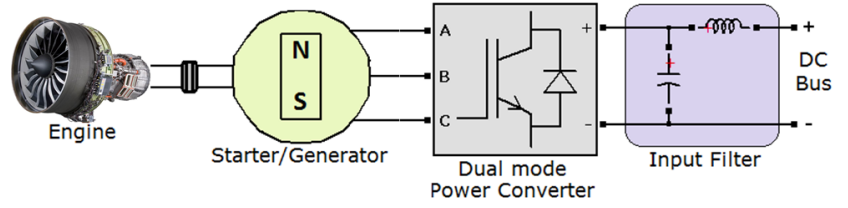

Fig. 1 Application of VSC in PM motor-drive for aerospace starter generator application

in Fig. 1 which shows a PM machine fed by a VSC system for starter/generator application. Note that the illustration of Fig. 1 shows that in starter/generator application, the VSC will operate as a inverter in machine mode whereas it will operate as a rectifier in generate mode. However, as the aim is to validate that the converter will achieve a power density of $17.5 \mathrm{~kW} / \mathrm{L}$ within the provided restricted envelope, only one operating mode is sufficient to validate the said claim and this can be done by using an RL load at the output instead of actual PM machine and operating the VSC in inverter mode.

The input of inverter, in such aerospace applications, is either a $270 \mathrm{~V}$ or a $540 \mathrm{~V}$ HVDC bus because such HVDC buses are now common in MEAs [2] as they are promising in terms of capacity and power density when compared with the traditional voltage levels [6]. The VSC, just as PM machine and electrical network, must be obey the constraint of power density set by the aircraft manufacturer. The progress in the development of semiconductor materials, e.g. Silicon Carbide (SiC) and Galium Nitride $(\mathrm{GaN})$, is acting as a key factor in achieving high power density power converters. This is mainly because such technologies are capable of high $d A / d t$ and $d V / d t$ therefore, allowing higher switching frequencies which consequently reduces the size of the input side DC-link capacitor and output side filter inductance. When compared with previous Silicon (Si) technology, improvements in volumetric power density up to a factor of 10 has recently been seen with $\mathrm{SiC}$ [7]. Various $\mathrm{SiC}$ based power converters with power densities ranging from $2 \mathrm{~kW} / \mathrm{L}$ up to $25 \mathrm{~kW} / \mathrm{L}$ have been reported in [7-10]. Not only that but a $50 \mathrm{~kW} / \mathrm{L}$ [11] and even a $70 \mathrm{~kW} / \mathrm{L}[12]$ cubic-shaped $\mathrm{SiC}$ based three-phase two-level (2L) inverter systems have also been introduced which indicate the feasibility of very high power density converters. However, in case when the demanded shape or envelope of the converter system is other than cubical, such as in the target aerospace applications of Fig. 2, then realising a compact converter becomes extremely challenging as not only the size but the 
position of electronic components including DC-link capacitors, gate driver ICs and isolated DC/DC supplies also

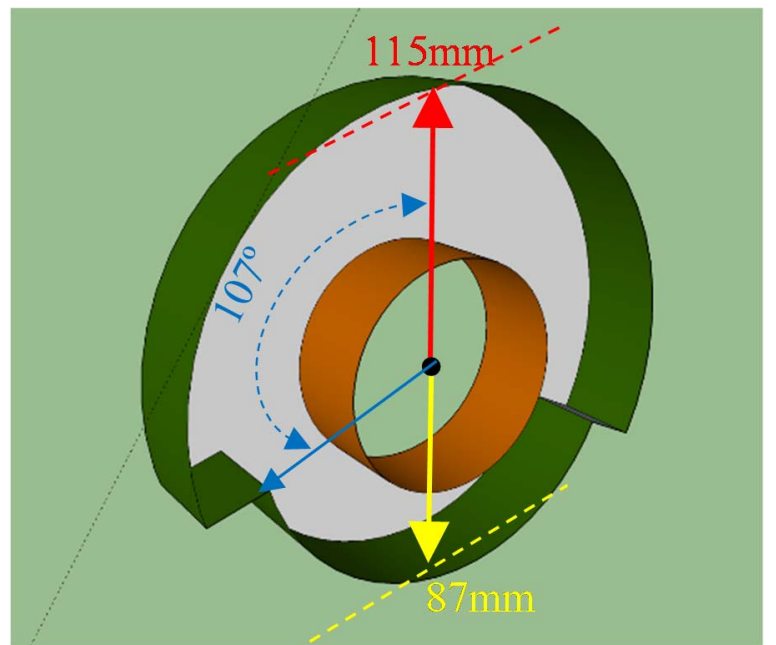

Fig. 2 Envelope/shape provided for converter by the aircraft manufacturer

becomes a constraint. This paper discusses the development and implementation of a $2 \mathrm{~L} 13 \mathrm{~kW}$ VSC for volume-restricted aerospace applications. The study is further divided into sections which discuss selection of semiconductor devices, converter topology, gate driver and power board designs and experimental validation.

\section{SElEction of The SeMiconductor DeVICES}

A wide range of semiconductor device technologies is available these days with $\mathrm{SiC}$ and $\mathrm{GaN}$ being most emergent but the choice between the mentioned technologies is made based on the application. Considering the application in hand which is VSC intended for use in PM drives in aircrafts, usually a very fast frequency is not preferable because the control platform e.g. DSP may not be able to perform calculations within the limited switching period specifically when a complex control technique such as sensor-less control is desired. A practical range of switching frequency of VSC in $\mathrm{PM}$ drive applications is from $30 \mathrm{kHz}$ to $50 \mathrm{kHz}$ [13]. Since, the advantages of $\mathrm{GaN}$ devices becomes dominant over those offered by SiCs for the switching frequencies only above
$100 \mathrm{kHz}[14]$ therefore, $\mathrm{SiC}$ devices are preferable for selected for the range of $30 \mathrm{kHz}$ to $50 \mathrm{kHz}$ switching frequency.

\section{SELECTION OF THE CONVERTER TOPOLOGY}

It must be noted that in the targeted application, the volume and the shape are the key limitations therefore, regarding selection of power converter topology maximum priority is given to the topology with lower volume. Although, new converter topologies, which improve reliability, performance and minimize the volume, can be also be proposed for such drive systems but then an extensive research becomes essential to get industrial approval. Therefore, only the existing topologies e.g. 2L VSC or three-level (3L) VSC were considered. Although, improvements in switching losses are seen when a $3 \mathrm{~L}$ VSC $[15,16]$ is used instead of a $2 \mathrm{~L}$ VSC but a $3 \mathrm{~L}$ VSC will have an increased switch count leading to increased volume because today's market lacks a single $3 \mathrm{~L} \mathrm{SiC}$ power module. Discrete devices can be used to form a $3 \mathrm{~L} \mathrm{VSC}$ but this will make the layout design more challenging because the tracks cascading the devices will give rise to stray inductances. In addition to this, the voltage at the input of VSC will be in low range i.e. $270 \mathrm{VDC}$ or $540 \mathrm{VDC}$ and to block this level of voltage, two switches in a leg are adequate and a $2 \mathrm{~L}$ VSC topology based on single-packaged-power module becomes more suitable. Note that the failure rate of converter is usually higher than that of the machine [17] therefore, for reliability concerns from the aircraft manufacturers, a redundant converter will be added to the system.

\section{CONVERTER DESIGN AND VALIDATION}

A SiC based 2L VSC was designed and populated based on the given envelope and the conceptual design of VSC was verified to fit within the given envelope. An exploded view showing how various PCB boards and cooling system will fit the envelope is illustrated in Fig. 3. A single PCB board was avoided and separate PCBs were used for gate driver and power boards in order to have ease of maintenance in the VSC system. The power board in the exploded view of Fig. 3 has a pair of 2L VSCs to satisfy discussed reliability concerns and the layout of each VSC is in a semi-circular shape. However, only a single semi-circular shaped 2L VSC has been manufactured and experimentally tested to check the

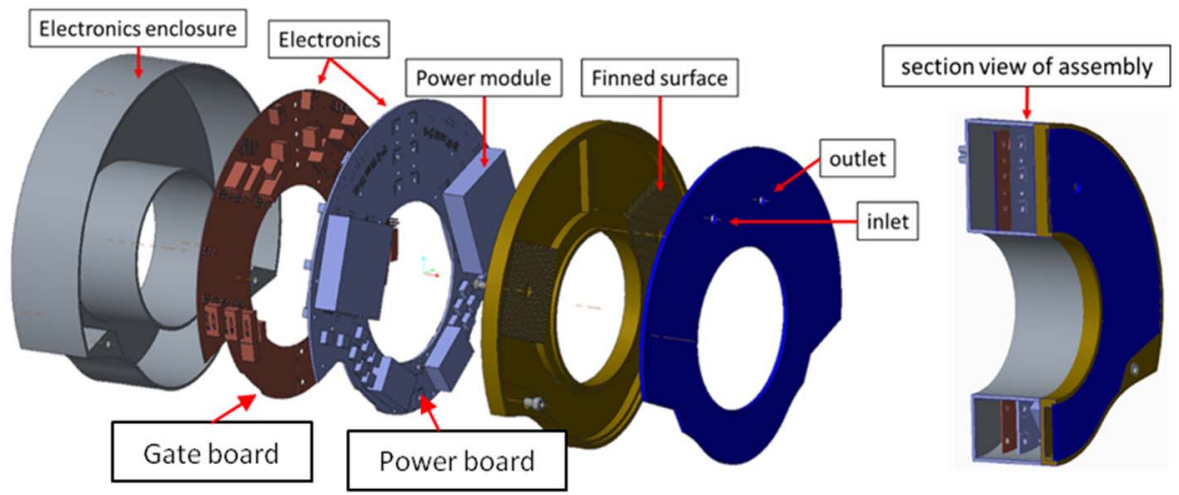

Fig. 3 Exploded view of VSC including cooling system 

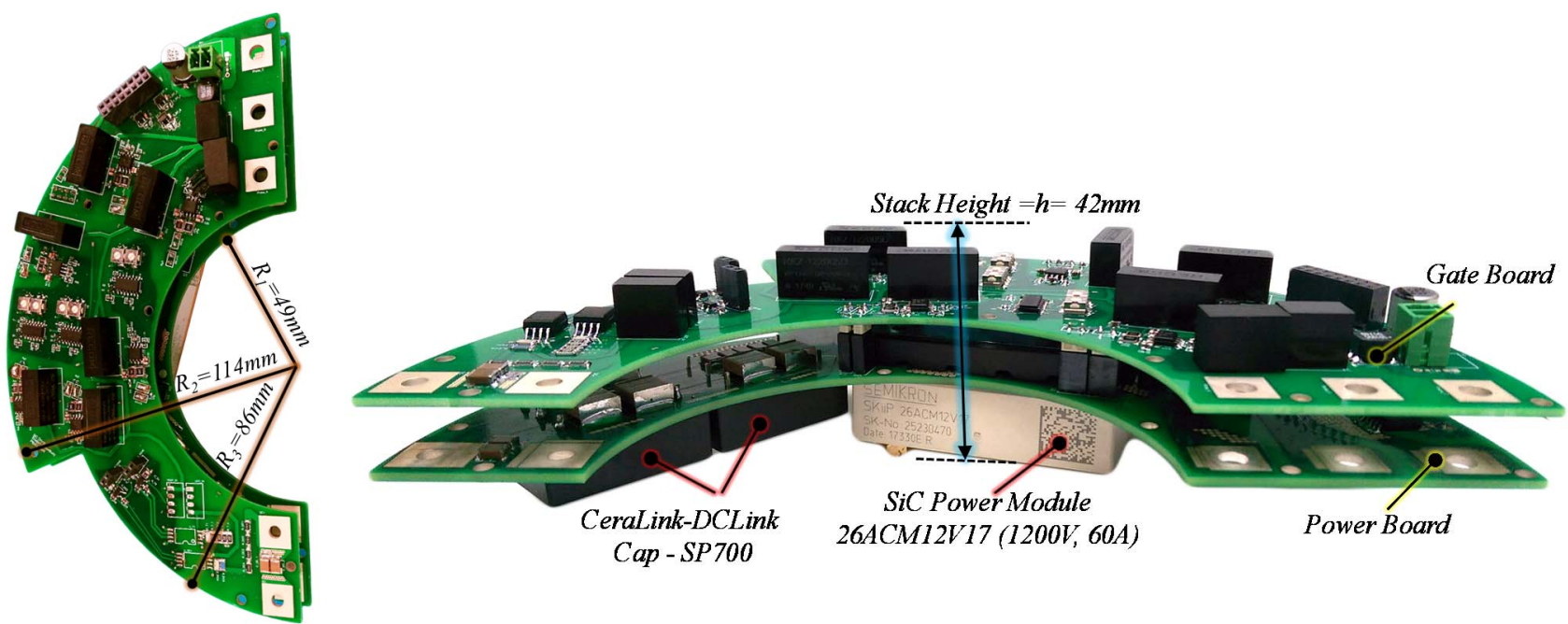

(a)

(b)

Fig. 4. Photos of the SiC based 2L three-phase converter system for aerospace application (a) Envelope of the converter highlighting its radial dimensions. (b) Axial view of the converter showing stack height of gate driver and power board.

feasibility of fitting the electronics within the envelope. Photos showing the radial and axial views of the developed VSC are presented in Fig. 4(a) and Fig. 4(b), respectively.

A. Device Selection

Considering the packing of the devices for VSC, discrete devices can offer lower volume but this makes the PCB layout more challenging as PCB tracks connecting the devices to form a 2L VSC will give rise to inductances. For this reason, a single power module (Skiip-packaged 26ACM12V17 power module), comprising a 2L VSC topology, was employed. The dimensions of the power module are $59 \mathrm{~mm} \times 52 \mathrm{~mm}$ which fits the boards as the radial width of board $\mathrm{R}_{2}-\mathrm{R}_{1}=65 \mathrm{~mm}$ which is greater than width of module i.e. $R_{2}-R_{1}>59 \mathrm{~mm}$. Note that the movement of the power module is limited and cannot be placed at the locations where the radial width is $\mathrm{R}_{3}-\mathrm{R}_{1}=37 \mathrm{~mm}$.

\section{B. DC-Link Capacitor Section}

The life of a VSC is largely dependent on the life of the DClink capacitor [18] and in traction and aerospace applications, where the DC-link capacitor is exposed to harsh environment and temperatures, employing an electrolytic capacitor will cause frequent maintenance as they have limited life, broad tolerances and in addition to this their ESR is large which leads to higher power losses. A new capacitor technology, known as Cera-Link capacitors, has recently been introduced which can offer a very low ESR in range of $4 \mathrm{~m} \Omega @ 100 \mathrm{kHz}$. Furthermore, it can offer $400 \%$ reduction in ESR value when the temperature rises from $25^{\circ} \mathrm{C}$ to $150^{\circ} \mathrm{C}$. The effective capacitance of this technology is above $100 \%$ i.e. maximum until a temperature of $100^{\circ} \mathrm{C}[19]$. Due to these reasons $2 \mathrm{x}$ $10 \mu \mathrm{F}$ CeraLink-SP700 DC-link capacitors and $8 \times 0.5 \mu \mathrm{F}$ were connected in parallel along with MLCC type ceramic capacitors to form a total capacitance of $25 \mu \mathrm{F}$.

C. Volumetric and Power Density Calculations

The volume (in litres) of the gate driver and power board for single-converter, shown in Fig. 4, was found to be $0.575 \mathrm{~L}$ by substitution of the values of $R_{1}, R_{2}$ and $R_{3}$ in (1). The volume of the whole cold plate including both the solid and the fluid, shown in exploded view of Fig. 3 is found out to be $0.341 \mathrm{~L}$ and hence the volume of cooling system per VSC is $0.170 \mathrm{~L}$. Therefore, the total volume of a $2 \mathrm{~L}$ VSC including cooling system becomes $0.745 \mathrm{~L}$.

$$
V=\frac{\pi h}{6 e^{3}}\left[R_{2}^{2}-3 R_{1}^{2}+2 R_{3}^{2}\right]
$$

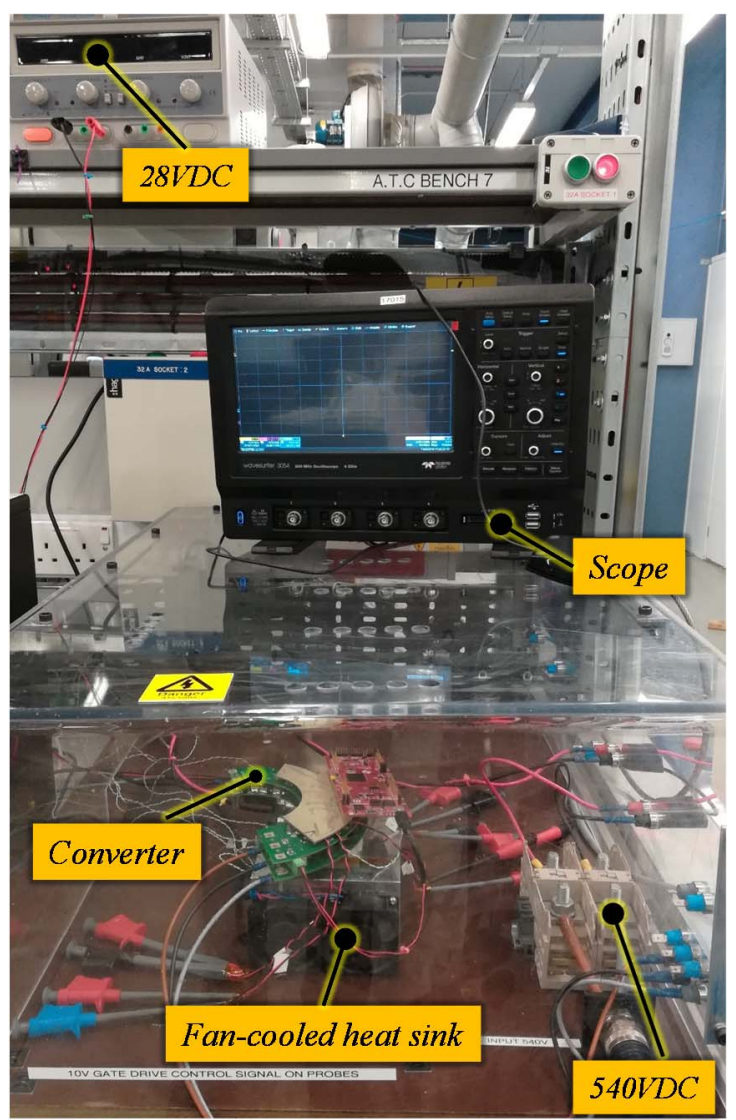

Fig. 5. Photo of the experimental setup of a SiC based 2L VSC for aerospace application 
Although, the SiC Skiip-packaged 26ACM12V17 module, highlighted in Fig. 4(b), is rated for a peak power of $72 \mathrm{kVA}$ but the ampere rating of 6-layered $20 z$ power board has been limited to a peak value of $40 \mathrm{~A}$ and the voltage rating is limited by the CeraLink-SP700 DC-link capacitors to peak value of 700VDC. The peak VA capability of each of $2 \mathrm{~L}$ power converter is $28 \mathrm{kVA}$ and is capable of delivering $13 \mathrm{~kW}$. Based on $13 \mathrm{~kW}$ of active power, the volumetric power density of VSC with cooling system is $17.5 \mathrm{~kW} / \mathrm{L}$. Note that this value of power density is calculated by considering the complete envelope of the converter and not merely by adding the volumes of the individual components. Evaluating the power density by adding the volumes of the individual components will not represent the actual power density of the converter as any un-used space/volume between the boards is not useful in terms of fitting additional electronics and therefore the whole envelope must be taken into account.

D. Experimental Validation of Inverter

An experimental setup has been built and the photo of which is shown in Fig. 5. It is important to mention that, for the sake of laboratory tests, a fan-cooled heatsink is used in the experimental rig to mimic the fluid based cooling system. Note that the thermal resistance of the fan-cooled heat sink matches with that of the fluid based cooling system and thus mimics the designed thermal system. The gate driver board is designed to accept 28VDC input thus can directly be connected to the centralised power network of the MEAs[2]. In gate board, the $28 \mathrm{VDC}$ are then level-shifted to generate $+18 \mathrm{~V}$ and $-2.3 \mathrm{~V}$ to drive $\mathrm{SiC}$ MOSFETs using isolated DC/DC converters. Each of the 6 gate driver circuits are supplied using 6 independent isolated and regulated DC/DC converters. Note that to comply with EMC requirements, an LC filter has been added at the input of each isolated $\mathrm{DC} / \mathrm{DC}$ converter. The inductor at the input of isolated $\mathrm{DC} / \mathrm{DC}$ converter limits the in-rush current which would otherwise cause increased temperature.

Table I

PARAMETERS For EXPERIMENTAL TEST OF CONVERTER

\begin{tabular}{|c|c|c|}
\hline Parameter & Symbol & Value \\
\hline DC-Link capacitor at input & $\mathrm{C}_{\mathrm{F}}$ & $25 \mu \mathrm{F}$ \\
\hline Filter inductor at output & $\mathrm{L}_{\mathrm{F}}$ & $2.5 \mathrm{mH}$ \\
\hline Load resistor & $\mathrm{R}$ & $8.9 \Omega$ \\
\hline Switching frequency & $\mathrm{f}_{\mathrm{sw}}$ & $40 \mathrm{kHz}$ \\
\hline Input DC voltage & $\mathrm{V}_{\mathrm{DC}}$ & $540 \mathrm{~V}$ \\
\hline
\end{tabular}

A negative voltage has been used at the gates of the $\mathrm{SiC}$ devices to ensure the turn-OFF of the $\mathrm{SiC}$ devices and different gate paths and resistor values are used for turn-ON and turnOFF of the devices. The path between the gate driver IC to the gate of the device is minimised and is kept similar, where possible, for all the six gate-driving circuits in order to achieve

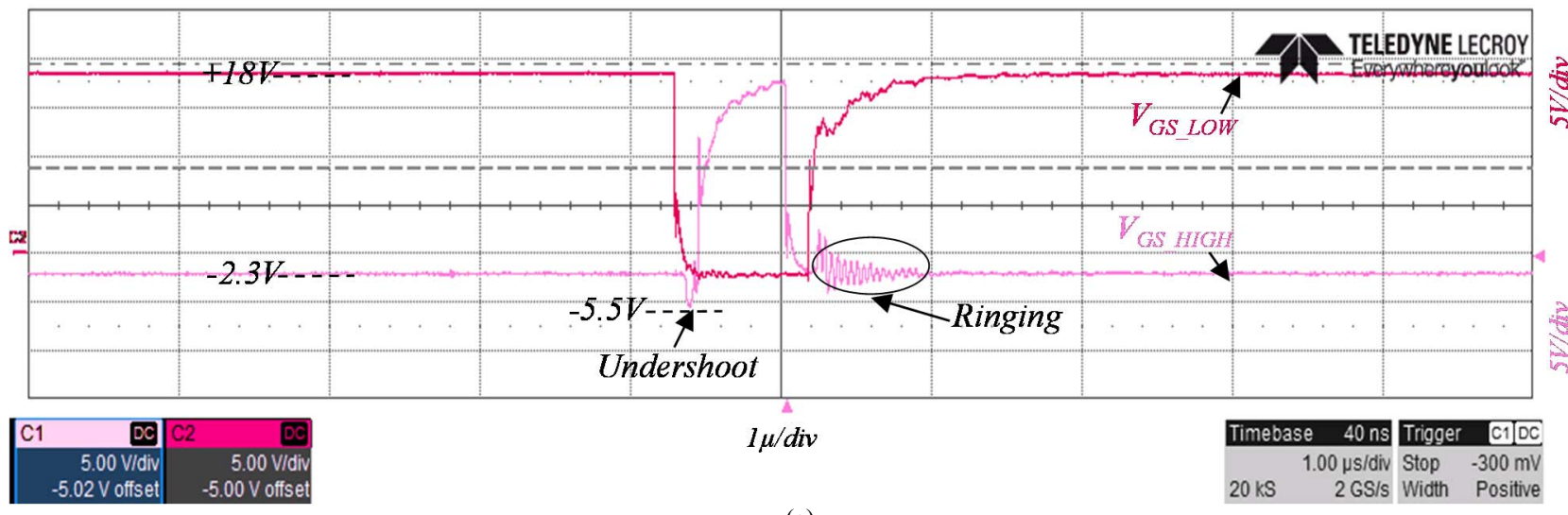

(a)

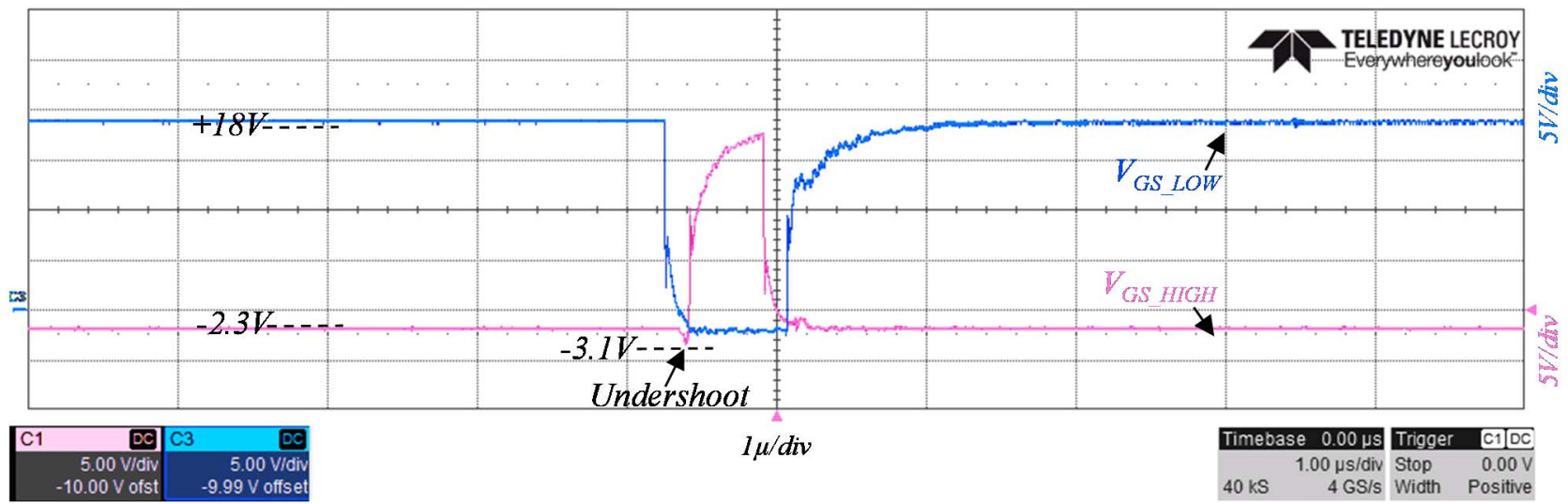

(b)

Fig. 6. Experimental gate driver signals of a single leg (high-side and low-side devices) when DC/AC VSC is operating at an active power of 13kW (a) High-side and low-side gate driver signals in case 1 (b) High-side and low-side gate driver signals in case 2 
similar switching performance but non-negligible stray inductance will still be present which will cause voltage spikes across gate-source of device when $\mathrm{dA} / \mathrm{dt}$ is large. Therefore, the gate driver board must be tested to check the performance and to do this, the power converter was operated at the rated power of $13 \mathrm{~kW}(540 \mathrm{~V}, 35 \mathrm{~A})$ with the parameters listed in Table I and the results of gate driver signals of one leg of converter, recorded using $200 \mathrm{MHz}$ band-width LeCroy HVD3102 probes, are presented in Fig. 6 in which the critical case of commutation is shown i.e. when duty cycle is minimum. In Fig. 6, $V_{G S \_L O W}$ corresponds to the low-side gate to source voltage whereas $V_{G S_{-} H I G H}$ represents high-side gate to source voltage. Results shown in Fig. 6(a) are for the case 1 when the gate resistor values of $R g_{O N}$ high $=3.5 \Omega$,

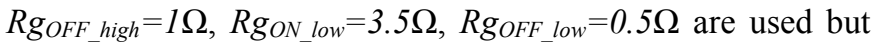
an under-shoot and ringing was observed. To improve this under-shoot, the gate resistor values were gradually increased until to case $2\left(R_{O N_{-} h i g h}=4 \Omega, \quad R g_{O F F_{-} h i g h}=1.5 \Omega\right.$, $\left.R g_{O N_{-} l o w}=3.5 \Omega, R g_{O F F_{-} l o w}=1.5 \Omega\right)$. The recorded waveforms, with case 2, are shown in Fig. 6(b) in which the peak undershoot has decreased to $-3.1 \mathrm{~V}$ and the oscillations are damped as well due to increase in charging time of gate capacitance. This has been done to reduce stresses, improve reliability and eventually increase the life of VSC [20].

The input supply 540VDC at the converter's input (listed in Table I) can either obtained by a cascade connection of two $+/$ 270VDC supplies or a single 540VDC supply[21]. For experimental test, 540VDC was obtained by series connection of two Delta-Elektronika SM500-CP90 each rated to provide $500 \mathrm{~V}, 90 \mathrm{~A}$ and results of Fig. 7 highlight the waveforms at different points of the converter. The three line to line voltages $\mathrm{V}_{\mathrm{ab}}, \mathrm{V}_{\mathrm{bc}}$ and $\mathrm{V}_{\mathrm{ca}}$ in Fig.7 (a) are recorded with $200 \mathrm{MHz}$ bandwidth probes and are clean from any un-wanted pulses due to accidental turn-ON of devices. To validate that the PWM output voltage has only the fundamental components in the low frequency range, the switching harmonics are filtered using the output inductor and the phase currents $\mathrm{I}_{\mathrm{a}}, \mathrm{I}_{\mathrm{b}}$ and $\mathrm{I}_{\mathrm{c}}$ are shown in Fig. 7(b). Furthermore, the peak value of the phase currents is $35 \mathrm{~A}$ and the input DC voltage, from Fig. 7(c), is $540 \mathrm{~V}$ which validate the $\mathrm{PCB}$ designs because the results obtained are at the rated $d A / d t$ and $d V / d t$. Input DC voltage and current have seen a ripple of $1.86 \%$ i.e. $\Delta \mathrm{V}_{\mathrm{dc}}=10 \mathrm{~V}$ and $\Delta \mathrm{I}_{\mathrm{dc}}=10 \mathrm{~A}$, respectively as shown in Fig. 7(d), when operated with parameters reported in Table I. Note that the results of Fig. 6 and Fig. 7 act as a feasibility study which demonstrate the expected power density of $17.5 \mathrm{~kW} / \mathrm{L}$ is achievable within the provided envelope and shape and that the gate driver and power boards are able to tolerate rated $d A / d t$ and $d V / d t$. The experimental losses of the converter, with an input power of $13 \mathrm{~kW}$, are found to be $320 \mathrm{~W}$ hence, an efficiency of $97.6 \%$.

\section{E. Thermal Performance}

The experimental waveforms presented in the preceding sub-section have confirmed the feasibility of achieving a restricted-shaped $17.5 \mathrm{~kW} / \mathrm{L} 2 \mathrm{~L} \mathrm{SiC}$ based power converter. However, looking at Fig. 4 (b), it can observed that the gate-

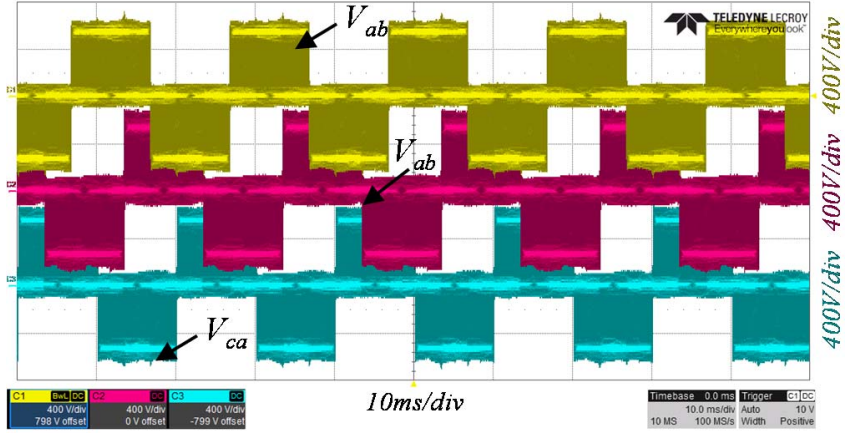

(a)

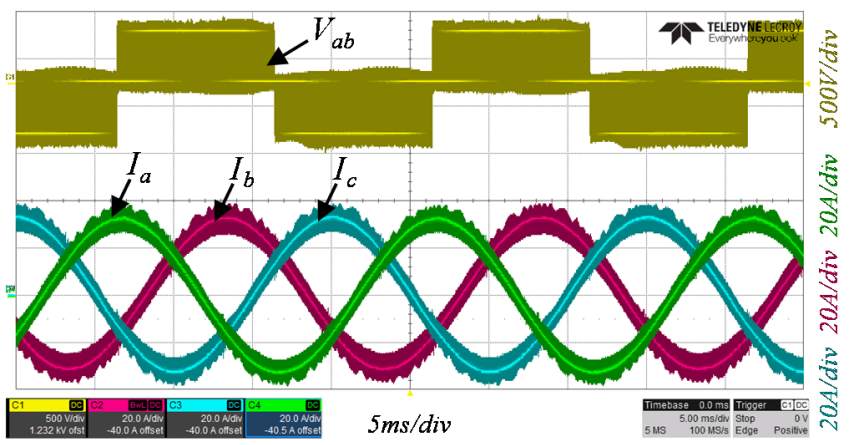

(b)

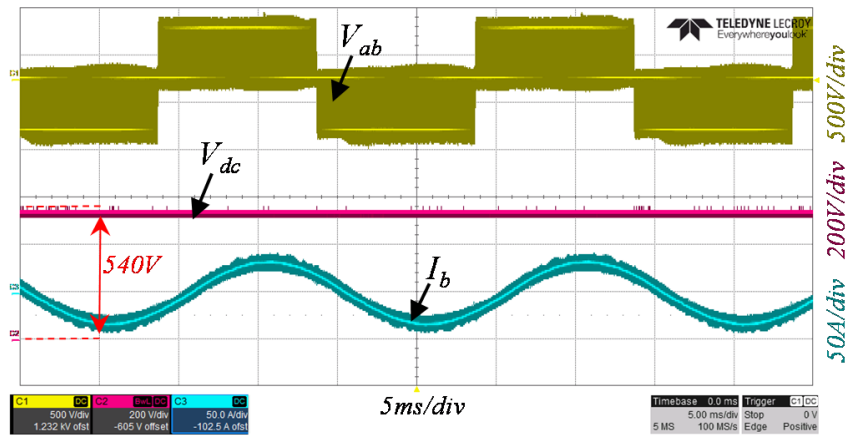

(c)

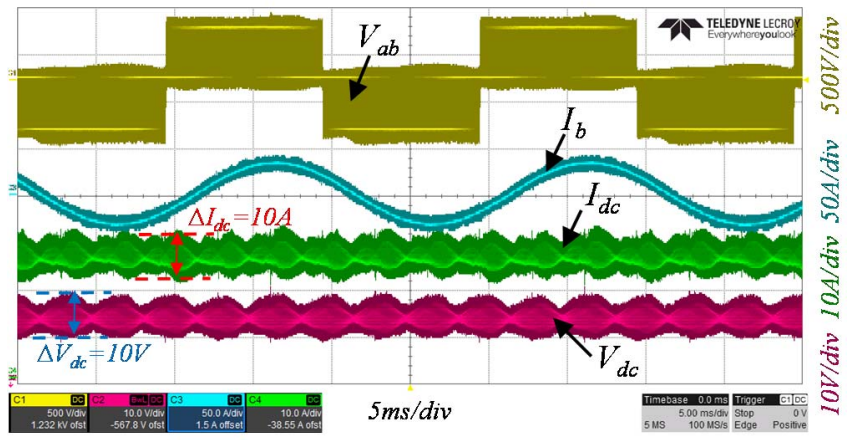

(d)

Fig. 7. Experimental waveforms at different points in the DC/AC VSC when operated at an active power of $13 \mathrm{~kW}$ (540VDC, 35A) (a) Three line-line voltages $V_{a b}, V_{b c}$ and $V_{c a}$. (b) $V_{a b}$ along with the three phase output currents $I_{a}, I_{b}$ and $I_{c}$. (c) $V_{a b}$ and $I_{b}$ and input voltage of 540VDC showing the operation is at rated voltage. (d) Zoomed view of input DC voltage showing voltage and current ripples of $10 \mathrm{~V}$ and $10 \mathrm{~A}$. 


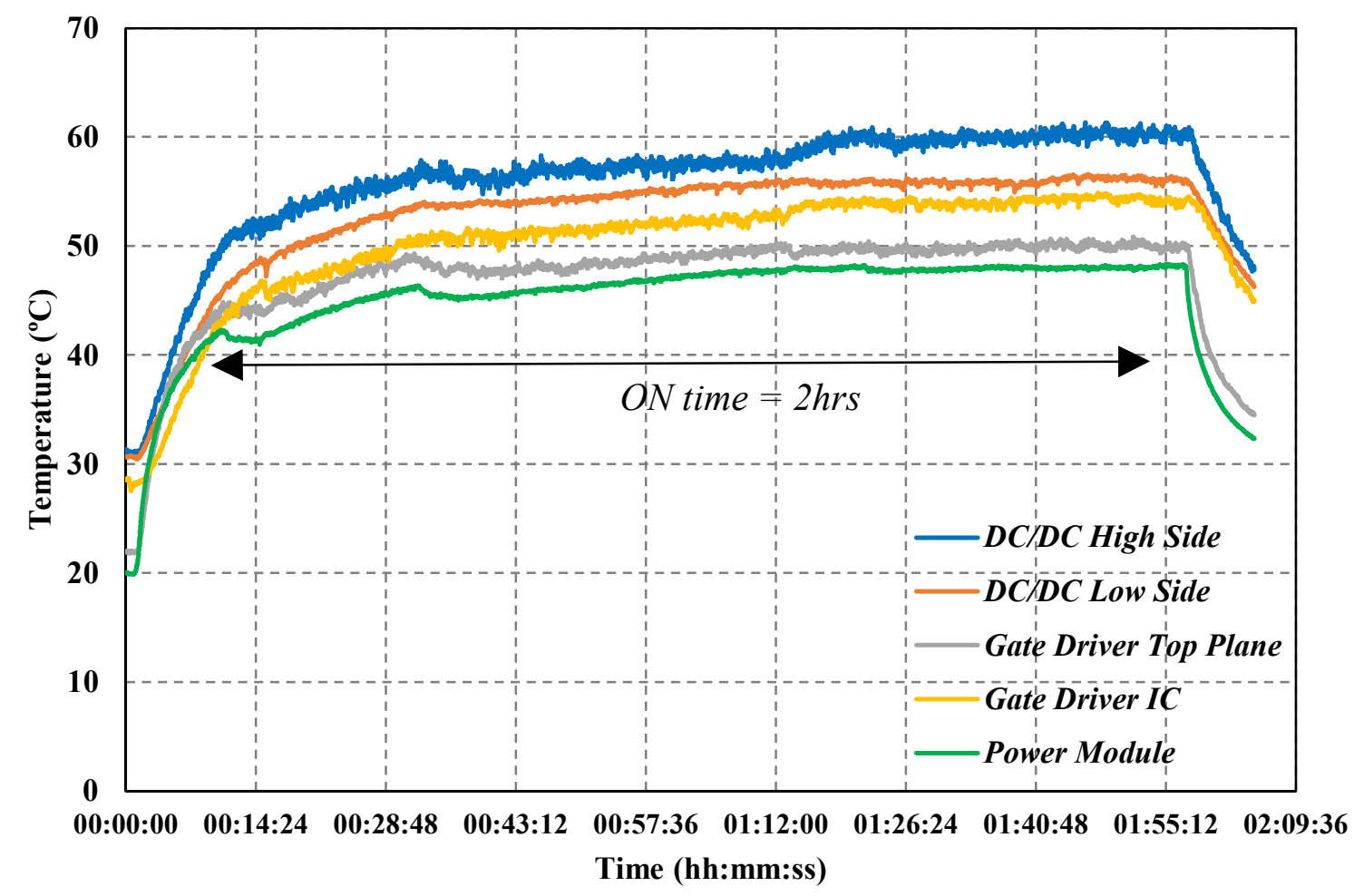

Fig. 8. Thermal performance of various crucial components of the designed $2 \mathrm{~L} \mathrm{SiC} \mathrm{based} \mathrm{power} \mathrm{converter} \mathrm{at} 13 \mathrm{~kW}$ continuous operation for 2 hours.

driver board and power board are close and the components are tightly packed together thus any rise in the temperature in the power module can cause the temperature of the gate board to increase as well. The temperature of the gate board must not exceed $85^{\circ} \mathrm{C}$ at any cost because the that is the maximum operating temperature of the isolated $\mathrm{DC} / \mathrm{DC}$ converters (RKZ-052005D/P) which therefore, acts as the threshold and bottleneck in the gate board in terms of maximum allowable temperature. Therefore, it is necessary to operate the converter at the rated power of $13 \mathrm{~kW}$ for the time until the temperatures are stabilized. To test this, the designed converter was operated at the rated power for a duration of 2 hours and the recorded experimental data from pico-scope is presented in Fig. 8. Note that only the temperatures of DC/DC converters of a single-leg i.e. of high and low side switches were observed because the three legs of inverter are identical in terms of layout and components. In addition to these, the temperature of the gate board, and gate driver IC (UCC5350SBD) are also crucial in terms of applying correct gate signals to the power modules. From Fig. 8, it can be noted that the temperatures have stabilized at $\mathrm{t}=01: 48: 48$ and that the maximum temperature of the $\mathrm{DC} / \mathrm{DC}$ converter is $62^{\circ} \mathrm{C}$ which is below the maximum operating temperature $\left(85^{\circ} \mathrm{C}\right)$ defined in the datasheet. The maximum operating temperature of the gate driver IC (UCC5350SBD) defined in the datasheet is $125^{\circ} \mathrm{C}$ and the final temperature after 2 hours of operation is $55^{\circ} \mathrm{C}$. The temperature of the top-plane of the gate driver board was stabilised to $50^{\circ} \mathrm{C}$ which is well within the temperature limit of the components such as decoupling ceramic capacitors, voltage regulators, and buffers. Finally, the temperature of the module is $48^{\circ} \mathrm{C}$ which is far below the maximum allowable temperature of $150^{\circ} \mathrm{C}$ for the module. Therefore, Fig. 8 confirms that the converter design is safe from thermal perspective. It is important to mention that any slow increase in the temperatures during the 2 hours of operation, in Fig. 8, is due to dissipated heat from the RL load which is near to converter.

\section{CONCLUSIONS}

This paper presented the feasibility study which discussed the development of a $97.6 \%$ efficient - $13 \mathrm{~kW} \mathrm{SiC}$ based $2 \mathrm{~L}$ power converter for special aerospace applications in which the envelope is restricted by the aircraft manufacturer.

The maximum volumetric power density achieved as a result of this study is $17.5 \mathrm{~kW} / \mathrm{L}$. This value has been calculated by considering the whole envelope covered by the converter and not merely by summing the individual volumes of the each components which would otherwise give a very high power density value. Converter design and improvements in the power density value are very challenging because the shape of the board is limited which restrains the components locations in terms of position and movement. However, further improvements are being made in layout to achieve higher volumetric power density and the further work also includes EMC tests to validate the compatibility. 


\section{ACKNOWLEDGEMENTS}

This project has received funding from the Clean Sky 2 Joint Undertaking under the European Union's Horizon 2020 research and innovation programme under grant agreement No 737814 .

\section{REFERENCES}

[1] Z. Zhang, J. Huang, Y. Jiang, W. Geng, and Y. Xu, "Overview and analysis of PM starter/generator for aircraft electrical power systems," CES Transactions on Electrical Machines and Systems, vol. 1, pp. 117-131, 2017.

[2] R. Liu, L. Xu, Y. Kang, Y. Hui, and Y. Li, "230 VAC/28 VDC high-power density power supply for more electric aircraft applications," The Journal of Engineering, vol. 2018, pp. 499-505, 2018.

[3] S. Bozhko, M. Rashed, C. I. Hill, S. S. Yeoh, and T. Yang, "FluxWeakening Control of Electric Starter-Generator Based on Permanent-Magnet Machine," IEEE Transactions on Transportation Electrification, vol. 3, pp. 864-877, 2017.

[4] F. Liu, L. Xu, Y. Li, Y. Kang, and Z. Wu, "Permanent magnet synchronous machine starter/generators based high-voltage DC parallel electric power system for the more electric aircraft," The Journal of Engineering, vol. 2018, pp. 565-569, 2018.

[5] M. R. Khowja, C. Gerada, G. Vakil, S. Q. Quadri, P. Wheeler, and C. Patel, "Design of an Integrated Inductor for $45 \mathrm{~kW}$ Aerospace Starter-Generator," in 2018 IEEE Transportation Electrification Conference and Expo (ITEC), 2018, pp. 570-575.

[6] J. Brombach, M. Jordan, F. Grumm, and D. Schulz, "Converter topology analysis for aircraft application," in International Symposium on Power Electronics Power Electronics, Electrical Drives, Automation and Motion, 2012, pp. 446-451.

[7] A. Bindra, "Wide-Bandgap Power Devices: Adoption Gathers Momentum," IEEE Power Electronics Magazine, vol. 5, pp. 22-27, 2018.

[8] C. Chen, Y. Chen, Y. Li, Z. Huang, T. Liu, and Y. Kang, "An SiCBased Half-Bridge Module With an Improved Hybrid Packaging Method for High Power Density Applications," IEEE Transactions on Industrial Electronics, vol. 64, pp. 8980-8991, 2017.

[9] C. Chen, Y. Chen, Y. Tan, J. Fang, F. Luo, and Y. Kang, "On the Practical Design of a High Power Density SiC Single-Phase Uninterrupted Power Supply System," IEEE Transactions on Industrial Informatics, vol. 13, pp. 2704-2716, 2017.

[10] Y. Shi, R. Xie, L. Wang, Y. Shi, and H. Li, "Switching Characterization and Short-Circuit Protection of $1200 \mathrm{~V} \mathrm{SiC}$ MOSFET T-Type Module in PV Inverter Application," IEEE Transactions on Industrial Electronics, vol. 64, pp. 9135-9143, 2017.

[11] K. Takao, S. Harada, T. Shinohe, and H. Ohashi, "Performance evaluation of all $\mathrm{SiC}$ power converters for realizing high power density of $50 \mathrm{~W} / \mathrm{cm}<\sup >3</$ sup $>$," in The 2010 International Power Electronics Conference - ECCE ASIA -, 2010, pp. 21282134.

[12] K. Yamaguchi, "Design and evaluation of SiC-based high power density inverter, $70 \mathrm{~kW} /$ liter, $50 \mathrm{~kW} / \mathrm{kg}$," in 2016 IEEE Applied Power Electronics Conference and Exposition (APEC), 2016, pp. 3075-3079.

[13] K. Shirabe, M. Swamy, J. Kang, M. Hisatsune, Y. Wu, D. Kebort, et al., "Advantages of high frequency PWM in AC motor drive applications," in 2012 IEEE Energy Conversion Congress and Exposition (ECCE), 2012, pp. 2977-2984.

[14] J. Xu and D. Chen. (2017, June) A Performance Comparison of GaN E-HEMTs Versus SiC MOSFETs in Power Switching Applications.

[15] A. Nawawi, C. F. Tong, S. Yin, A. Sakanova, Y. Liu, Y. Liu, et al., "Design and Demonstration of High Power Density Inverter for Aircraft Applications," IEEE Transactions on Industry Applications, vol. 53, pp. 1168-1176, 2017.
Q. Guan, C. Li, Y. Zhang, S. Wang, D. D. Xu, W. Li, et al., "An Extremely High Efficient Three-Level Active Neutral-PointClamped Converter Comprising SiC and Si Hybrid Power Stages," IEEE Transactions on Power Electronics, vol. 33, pp. 8341-8352, 2018

[17] D. Zhou, F. Blaabjerg, T. Franke, M. Tønnes, and M. Lau, "Comparison of Wind Power Converter Reliability With LowSpeed and Medium-Speed Permanent-Magnet Synchronous Generators," IEEE Transactions on Industrial Electronics, vol. 62, pp. 6575-6584, 2015.

[18] H. Wang and F. Blaabjerg, "Reliability of Capacitors for DC-Link Applications in Power Electronic Converters-An Overview," IEEE Transactions on Industry Applications, vol. 50, pp. 35693578,2014

[19] D. Neumayr, D. Bortis, J. W. Kolar, M. Koini, and J. Konrad, "Comprehensive large-signal performance analysis of ceramic capacitors for power pulsation buffers," in 2016 IEEE 17th Workshop on Control and Modeling for Power Electronics (COMPEL), 2016, pp. 1-8.

[20] A. Fayyaz and A. Castellazzi, "High temperature pulsed-gate robustness testing of $\mathrm{SiC}$ power MOSFETs," Microelectronics Reliability, vol. 55, pp. 1724-1728, 2015.

[21] F. Xiaohu and A. V. Radun, "SiC based solid state power controller," in 2008 Twenty-Third Annual IEEE Applied Power Electronics Conference and Exposition, 2008, pp. 1855-1860. 